\title{
Finding biomarkers in non-model species: literature mining of transcription factors involved in bovine embryo development
}

Nicolas Turenne ${ }^{1 * \dagger}$, Evgeniy Tiys $^{2 \dagger}$, Vladimir Ivanisenko ${ }^{2 \dagger}$, Nikolay Yudin ${ }^{5 \dagger}$, Elena Ignatieva ${ }^{6 \dagger}$, Damien Valour ${ }^{3,4 \dagger}$, Séverine A Degrelle $3,4+$ and Isabelle Hue $3,4+$

\footnotetext{
* Correspondence: nturenne@jouy. inra.fr

${ }^{\dagger}$ Equal contributors

${ }^{1}$ INRA, SenS, UR1326, IFRIS,

Champs-sur-Marne F-77420, France Full list of author information is available at the end of the article
}

\begin{abstract}
Background: Since processes in well-known model organisms have specific features different from those in Bos taurus, the organism under study, a good way to describe gene regulation in ruminant embryos would be a species-specific consideration of closely related species to cattle, sheep and pig. However, as highlighted by a recent report, gene dictionaries in pig are smaller than in cattle, bringing a risk to reduce the gene resources to be mined (and so for sheep dictionaries). Bioinformatics approaches that allow an integration of available information on gene function in model organisms, taking into account their specificity, are thus needed. Besides these closely related and biologically relevant species, there is indeed much more knowledge of (i) trophoblast proliferation and differentiation or (ii) embryogenesis in human and mouse species, which provides opportunities for reconstructing proliferation and/or differentiation processes in other mammalian embryos, including ruminants. The necessary knowledge can be obtained partly from (i) stem cell or cancer research to supply useful information on molecular agents or molecular interactions at work in cell proliferation and (ii) mouse embryogenesis to supply useful information on embryo differentiation. However, the total number of publications for all these topics and species is great and their manual processing would be tedious and time consuming. This is why we used text mining for automated text analysis and automated knowledge extraction. To evaluate the quality of this "mining", we took advantage of studies that reported gene expression profiles during the elongation of bovine embryos and defined a list of transcription factors (or TF, $n=64$ ) that we used as biological "gold standard". When successful, the "mining" approach would identify them all, as well as novel ones.

Methods: To gain knowledge on molecular-genetic regulations in a non model organism, we offer an approach based on literature-mining and score arrangement of data from model organisms. This approach was applied to identify novel transcription factors during bovine blastocyst elongation, a process that is not observed in rodents and primates. As a result, searching through human and mouse corpuses, we identified numerous bovine homologs, among which 11 to $14 \%$ of transcription factors including the gold standard TF as well as novel TF potentially important to gene regulation in ruminant embryo development. The scripts of the workflow are written in Perl and available on demand. They require data input coming from all various databases for any kind of biological issue once the data has been prepared according to keywords for the studied topic and species; we can provide data sample to illustrate the use and functionality of the workflow.

(Continued on next page)
\end{abstract}

\section{() Biomed Central}

(c) 2012 Turenne et al.; licensee BioMed Central Ltd. This is an Open Access article distributed under the terms of the Creative Commons Attribution License (http://creativecommons.org/licenses/by/2.0), which permits unrestricted use, distribution, and reproduction in any medium, provided the original work is properly cited. 
(Continued from previous page)

Results: To do so, we created a workflow that allowed the pipeline processing of literature data and biological data, extracted from Web of Science (WoS) or PubMed but also from Gene Expression Omnibus (GEO), Gene Ontology (GO), Uniprot, HomoloGene, TCoF-DB and TFe (TF encyclopedia). First, the human and mouse homologs of the bovine proteins were selected, filtered by text corpora and arranged by score functions. The score functions were based on the gene name frequencies in corpora. Then, transcription factors were identified using TCOF-DB and double-checked using TFe to characterise TF groups and families. Thus, among a search space of 18,670 bovine homologs, 489 were identified as transcription factors. Among them, 243 were absent from the highthroughput data available at the time of the study. They thus stand so far for putative TF acting during bovine embryo elongation, but might be retrieved from a recent RNA sequencing dataset (Mamo et al. , 2012). Beyond the 246 TF that appeared expressed in bovine elongating tissues, we restricted our interpretation to those occurring within a list of 50 top-ranked genes. Among the transcription factors identified therein, half belonged to the gold standard (ASCL2, c-FOS, ETS2, GATA3, HAND1) and half did not (ESR1, HES1, ID2, NANOG, PHB2, TP53, STAT3).

Conclusions: A workflow providing search for transcription factors acting in bovine elongation was developed. The model assumed that proteins sharing the same protein domains in closely related species had the same protein functionalities, even if they were differently regulated among species or involved in somewhat different pathways. Under this assumption, we merged the information on different mammalian species from different databases (literature and biology) and proposed 489 TF as potential participants of embryo proliferation and differentiation, with (i) a recall of 95\% with regard to a biological gold standard defined in 2011 and (ii) an extension of more than 3 times the gold standard of TF detected so far in elongating tissues. The working capacity of the workflow was supported by the manual expertise of the biologists on the results. The workflow can serve as a new kind of bioinformatics tool to work on fused data sources and can thus be useful in studies of a wide range of biological processes.

\section{Background}

\section{Mining context}

Molecular-genetic data obtained from model organisms are widely used in studies of biological processes. The problem is that the processes studied in the well-known model organisms often have specific features different from those in related non-model organisms. For this reason, a single model organism cannot give a complete idea of a process of interest. Development of bioinformatics approaches that allow integration of available information on gene function in model organisms taking into account their specificity is therefore an important task. This task is relevant to almost all areas of biology, including biomedicine, veterinary, and agriculture. For example, studies of embryo development in ruminants are important to i) understand embryonic loss, especially in high producing dairy cows and ii) compare developmental processes across species. However, molecular-genetic data on ruminant embryo development are scant and blastocyst elongation is not observed in rodents and primates; as a result, the number of well-studied organisms to refer to is limited. A good way to describe gene regulation in embryo development from ruminants would be a species-specific consideration of closely related species to cattle, such as sheep or pig, along with the well-studied model organisms, such as human and mouse. The current study offers an approach for knowledge acquisition on molecular-genetic regulation in any organism based on 
literature mining and integration of data sources from model organisms. This approach was applied to identify transcription factors acting in ruminant embryo development. We analyzed data on trophoblast proliferation and differentiation, embryogenesis, stem cells and cancer concerning cattle, human, mouse, rat, sheep, pig and horse, that were reported in PubMed and WoS. As a result, we identified novel genes potentially important to gene regulation in ruminant embryo development. These results will be helpful to design further biological experiments on ruminant embryo development but a similar approach would be useful to study other biological processes using data sources from other model organisms in either animals or plants. Approaches to search for articles that describe molecular-genetic mechanisms underlying complex biological processes have been developed. For example, a service enabling literature search and ranking based on their biological relevance to gene sets has been presented recently [1]. However, our approach is better in tune with ongoing issues in text-mining such as feature selection and fusion of literature and biological databases [2]. In animal sciences, text-mining just starts to be in the scope of in silico methods [3] and TF Encyclopedia proves the interest around transcription factors in life sciences [4].

\section{Biological issue}

A characteristic feature of blastocyst development in ruminants (cattle, sheep) and in pig is the elongation process (Figure 1). It is relevant to note that blastocyst elongation is not observed in rodents (mainly mouse, rat) and primates (human, monkey) $[5,6]$. It is observed in a few ungulates (pig), not in others (horse) however.

In contrast to cattle, there is an abundance of data on human trophoblast proliferation [7] and differentiation [8] or mouse trophoblast development $[9,10]$. Cancer research also disclosed an abundance of data on proliferative and invasive properties, thereby providing evidence for molecular circuits shared with human trophoblast cells [7]. Moreover, a special kind of trophoblastic cancer, usually of the placenta - choriocarcinoma type - was used to derive choriocarcinoma cell lines, frequently used to study trophoblast properties (Rcho-1, for example) [11], and to elucidate transcriptional regulation of a bovine trophoblast-specific gene, such as the IFN-tau $[12,13]$. Stem cell research also provides molecular data on trophoblast stem cells in mouse and human [14,15].

In addition to the text mining issue, we addressed here inter-specific differences in proliferation and differentiation, whose molecular bases are likely common over species and cell types. The total number of published scientific texts on the studied organisms

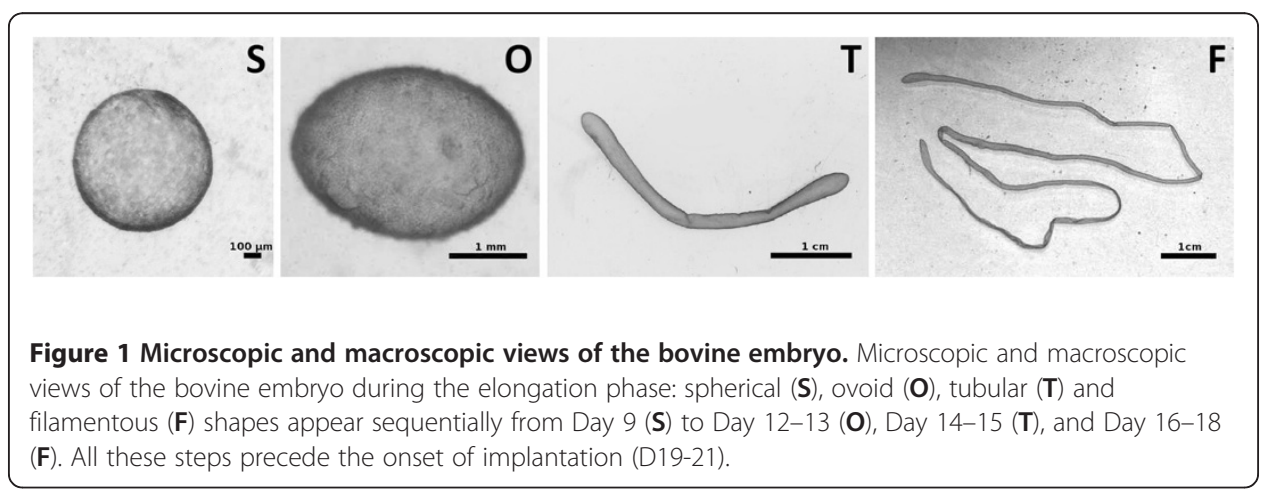


is great; therefore, computer-aided systems must be used for automated knowledge extraction. Our main goal was to search for novel transcriptional regulators involved in the development of bovine extra-embryonic tissues using a new text mining approach (a transcription factor or TF is a protein that binds to specific DNA sequences, activating or inhibiting the recruitment of RNA polymerase to specific genes; see the Transcription Factor Encyclopedia [4]). Text mining in biology is a well-established practice to identify genes and their possible interactants $[16,17]$ that is not much used in animal science [3]. Biological text mining focuses on the following tasks: (1) article classification, (2) protein and gene name recognition and (3) detection of protein-protein interaction pairs [18]. The F-score (balance precision and recall) was around 92\% (weighting contribution of many classifiers, from 82 to $87 \%$ ) for task 2, and the F-score was $29 \%$ for task 3 with pattern-based approaches [18]. The event extraction for biological entities became promising for information extraction [19]. Like in a jigsaw puzzle, each document is mined to get a piece of knowledge for a gene identified in sentences in a way to build its context: interactome, localization of gene products, biological processes involving the gene [20-23]. Natural language processing and text-mining of scientific articles can be a tool for digging out a hidden piece of knowledge and for enriching biological data analysis [24]. Our approach is original in the sense that we divide the bulk of literary facts into specialized sub-topics for the topic on which we focused. We introduced the concept of the subcorpus. To do so, at the first step we reduced the list of species to 7 (cattle, human, mouse, rat, sheep, pig and horse) and the list of keywords to 3: trophoblastic (tro), extraembryonic (ex), choriocarcinoma (cho). Our main goal was thus the identification of factors regulating gene expression and growth in the bovine trophoblast as a major contribution to elongation of the blastocyst before its implantation. To achieve this goal, we (i) took into account information from available studies in other species and (ii) identified shared genes or proteins through common Pfam domains (as in [25]) and HomoloGene records. As known, the protein domain is the evolutionary conserved unit of a protein that performs a particular function [26-29] but not all proteins are described by a Pfam.

The hypothesis search space was gradually reduced from about 18,670 putative genes (in Homologene/UniProtKB/TrEMBL) to a ranked list of around 1,000 proteins (Figure 2). Ranking was the first step in selecting a pool of genes that can be arranged in an interaction network [26]; the second step was to identify genes, among this top list, involved in regulatory interactions.

\section{Methods}

Databases

Our study benefited from concomitance of information scattered over several databases. It is related to a heterogeneous data exploration topic (or heterogeneous data mining).

Eight databases were used for processing:

- PubMed and Web of Science

PubMed (formerly Medline) from NCBI is the most scientific text database specialized in biology and medicine; indexing more than 20 million publications in the form of records but recently $30 \%$ are available as free full texts. The text database called Web 


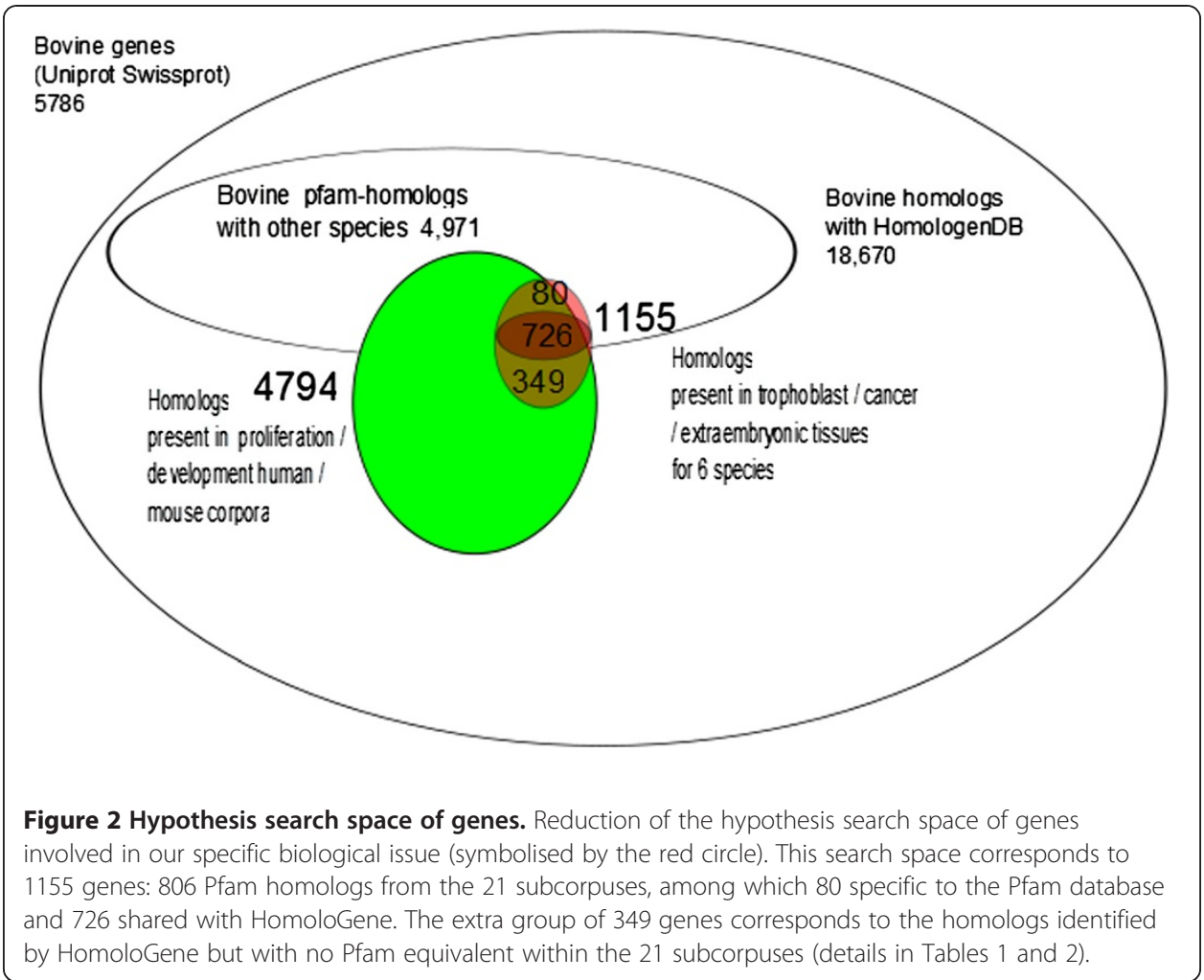

of Science (formerly ISI) from Thomson Reuters consists of more than 45 million publications for any topics, it is mainly used for science assessment. We developed a number of subcorpora about species and biological processes from databases.

- Uniprot

This database from EBI offers knowledge of all the known or putative proteins. Uniprot proposes a file, 'UniprotKB', consisting of records for each protein. These were records derived from the TrEMBL database (3,513,283 proteins « not reviewed » hence not completely known) and from the Swiss-Prot database (155,669 proteins « reviewed » or definitely described). From this file, we decided to extract codes about "reviewed" proteins and extracted information from each species. Table 1 shows the distribution of genes described with the Uniprot/Swiss-Prot codes per species.

Table 1 Distribution of protein/gene IDs

\begin{tabular}{lrrr}
\hline Files & Proteins (Uniprot) & Proteins (Pfam) & HomoloGene datasets \\
\hline SHEEP & 447 & 409 & 0 \\
HORSE & 280 & 265 & 0 \\
PIG & 1,374 & 1,264 & 0 \\
RAT & 7,554 & 6,670 & 19,921 \\
HUMAN & 20,286 & 16,478 & 19,062 \\
MOUSE & 16,307 & 13,944 & 21,076 \\
BOVINE & 5,786 & 4,971 & 18,670 \\
\hline
\end{tabular}

Distribution per species of the number of proteins/genes having Uniprot IDs (left) and at least one Pfam domain (center) or an HomoloGene item with the Bovine species (right). 
- $\mathrm{GO}$

Gene Ontology from a 20 Institutions consortium is a hierarchy of concepts. It can be useful for getting functional annotation as linguistic concept in such a concept tree to understand the role of protein. We used tags of GO included in Uniprot frames.

- Pfam

The Pfam database (or Protein families) from Sanger Institute consists of at least 12,000 functional domains. A domain is a molecular structure (a DNA sequence associated with a three-dimensional structure), whose properties are preserved over evolution of species and between genomes. Domains contribute to the properties of proteins.

- HomoloGene

HomoloGene is a system from NCBI for automated detection of homologs among annotated genes of several completely sequenced eukaryotic genomes. Together with human, mouse and rat, HomoloGene (Release 66) contains 18,670 bovine genes, placed in 17,472 homology groups.

- GEO

GEO is a database from NCBI of experimental raw datasets, generally microarrays, indexing around 2,800 datasets. We used a dataset named GDS1003 derived from the microarray study of [30] on embryogenesis and early fetal development: time course for bovine embryo [30]. The number of RNA coding sequences was 1,950.

- TcoF-DB

TcoF-DB from King Abdullah University is a database that includes a highly accurate set of 1365 human TFs [31]. Data were extracted from resources: i) a census of human TFs previously published by [32] that was regarded to be a gold standard due to the meticulous way it was created; ii) TRANSFAC, a very well known database on TFs [33]; iii) TFCAT [34] that compiles the mouse TF genes. For these genes, human orthologs were identified by the TcoF-DB team. It must be highlighted that each TF in the TcoF-DB list was curated manually at some point during the data integration.

The crucial step was how to bridge objects from all these independent databases to use information about our starting pool of bovine genes. The object here was the gene (and its product(s), i.e., its protein(s)).

The geneticist usually considers a few differences between a gene and its related protein, which have often the same designation in a publication. We deliberately chose a unique key for a gene as a meta-language between all these databases (gene name, Uniprot ID). This choice was based on (1) usage of both tabular and text databases (2) consensus in the bioinformatics community of researchers, 'molecular biologists', that the Uniprot database is universal. For instance, gene names in the microarray data of [30] were transformed into Uniprot IDs using the tool available at http://niaid.abcc.ncifcrf. gov/. In contrast to Uniprot ID, which is unique to a protein, a gene name may not be used regularly in its form; this is why synonyms of gene names must be taken into account (some synonyms are cited in the Uniprot database).

\section{General analytical workflow for gene identification}

Our objective was to identify and classify the proteins involved in trophoblast development. The initial search space consisted of the 18,670 hypothetical bovine proteins (Figure 2). We chose the genes well-described in the Swiss-Prot database, not more than 5,786. 
At the next step, we looked through the functional domains of the bovine genes to identify genes from other species that shared the same domains. They were considered as homologs, since they performed probably the same operating functions. In this way, we further reduced the hypothesis search space to about 4,971 for human and mouse. Finally, the literature concerned with genes was taken into consideration in the workflow to infer information for some genes active in embryonic development or proliferation. To do so, we had to build corpora for each species and for each process (i.e., subcorpora).

Figure 3 shows a rough workflow that has two parts. The first branch (yellow) got data from the database to compute the Pfam homologs. They were exported by ranking according to scores. The second branch following the first is beyond the scope of this paper. The list of genes was input to organize their links as an associative network (green branch) taking into account also the same subcorpora used in the yellow branch.

Details of the yellow branch are given in Figure 4. In the upper part (rose frame) the workflow has the objective to get data and make feature selection from raw data and encyclopedic data from heterogeneous databases described above. Genes to be analyzed are identified in both Uniprot/Swissprot and high-throughput data concerning the target species, in our case Bos taurus. At this step, queries to extract data files were names of species. The script to combine information is called ortho and is written in Perl. It generated homologs with the help of functional domains from the Pfam database between cattle and each species, pairwise, in separate exported files. Descriptions were from the collections of publications for which queries were defined by the process names. Ortho script was also able to compute the most representative Pfam IDs of each species (exclusive domains relative to other species and most frequent domains). The matrix of Boolean vectors for the presence or the absence of the 806 Pfam homologs within the 21 corpora was generated.

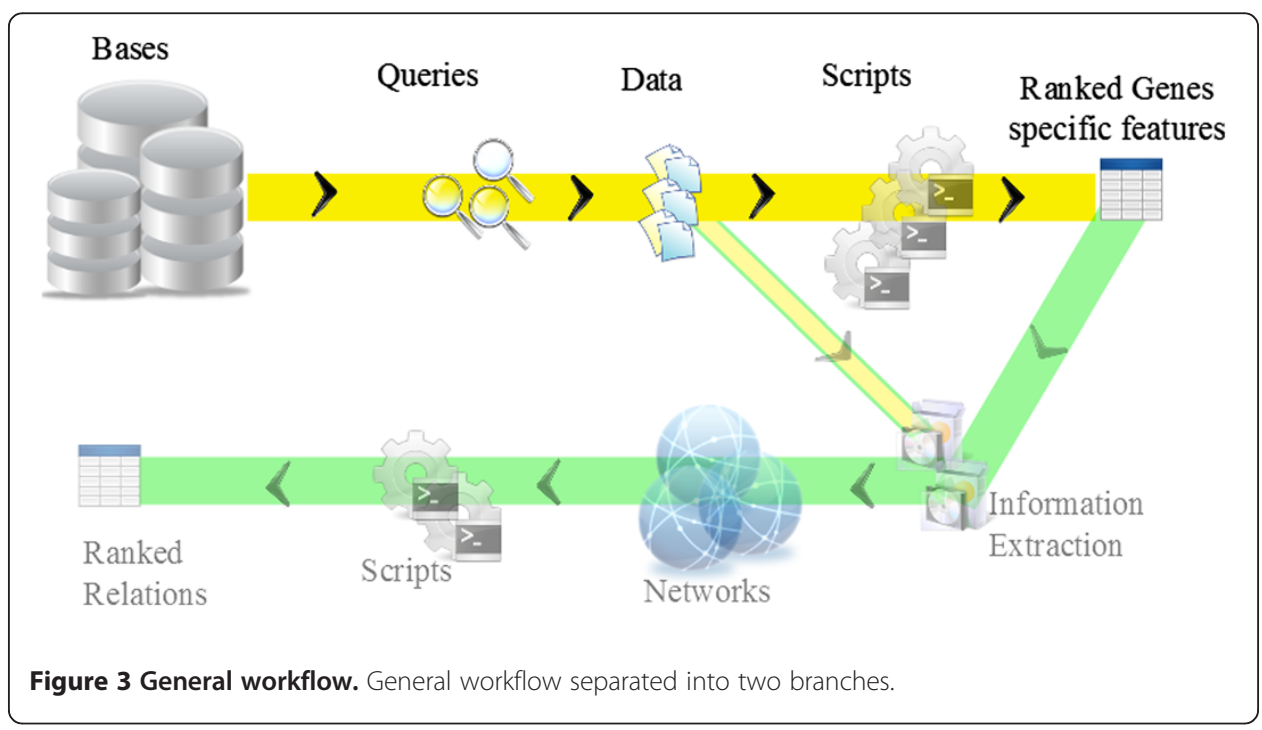




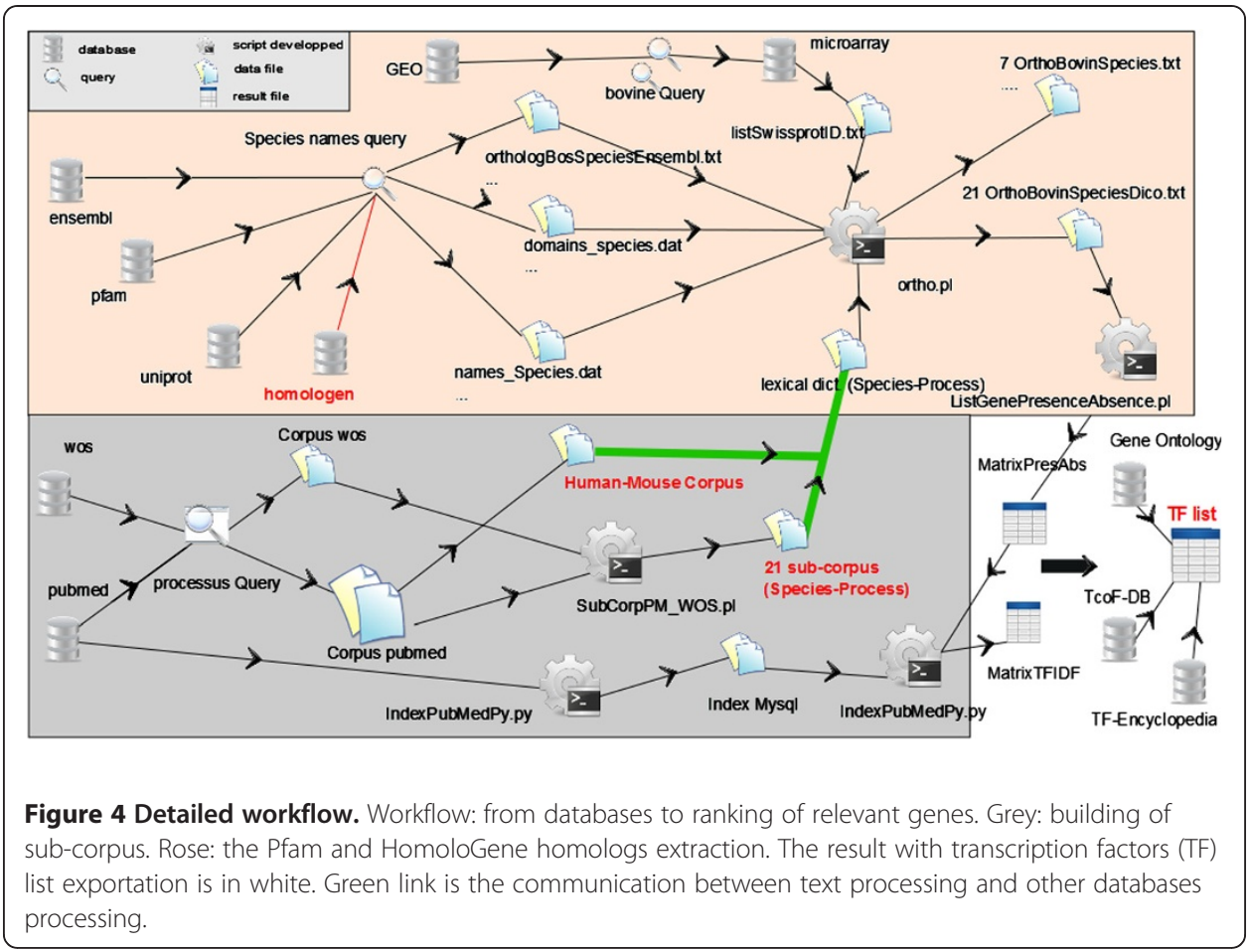

\section{Identification of transcription factors among the top genes}

a) 11 to $12 \mathrm{TF}$ in the 50 top genes with the Pfam

Transcription factors are proteins that bind to specific DNA sequences, thereby controlling the flow (or transcription) of genetic information from DNA to mRNA. The characteristic feature of TFs is that these proteins possess a sequence specific DNA binding domain. Two approaches were combined to identify TFs among the 50 top genes. First, the gene functions given by GO were analyzed. The presence of GO terms "sequence-specific DNA binding transcription factor activity" "transcription regulator activity", "bHLH transcription factor binding", "transcription activator activity", "DNA binding" was considered as an evidence that the protein is a transcription factor or is involved in some way in transcription regulation. Taking into account the fact that GO annotations are incomplete and in the majority of cases, inferred by electronic annotation, we made also use of the TcoF-DB set of 1,365 human transcription factors which was created very accurately [31]. For these human TFs from the TcoF-DB collection, bovine orthologous genes from each 50 top gene sets were identified. Further manual curation of revealed candidate proteins demonstrated that the results of the two approaches were in a good agreement (Additional file 1).

b) around $150 \mathrm{TF}$ among the 1,155 genes from the TF-IDF-21subcorpora (HomoloGene): we used the TcoF-DB and TF encycopledia to identify the TF families present in this gene sampling, out of the 3 to 400 DNA binding families identified nowadays [4].

c) about $500 \mathrm{TF}$ within the 4,794 genes in the TF-IDF human/mouse corpora (HomoloGene), using the same tools: TcoF-DB and TF encycopledia. 


\section{Results}

\section{Identification of Pfam homologs}

To make the information from the model species applicable to cattle, we defined homology between bovine proteins and human, mouse, rat, sheep, pig and horse proteins using Pfam functional domains. These domains are the amino acid sequences, whose structure and role in protein function remained stable during species evolution. Table 1 presents the number of proteins stored in the Pfam database for the 7 species listed above. Clearly, it seemed at first that most proteins of the tabulated species were described by Pfam domains.

The solution suggested for the detection of proteins with functions similar to those of cattle (the Pfam homologs) is based on (1) consideration of the bovine genes whose proteins have at least one Pfam domain and (2) search for proteins of other species, which share all the Pfam domains of a given bovine protein.

Figure 5 presents the distribution of the number of Bos taurus proteins having Pfam homologs in the examined species. As seen in the figure, from 75 to $85 \%$ of the bovine proteins have human, mouse and rat homologs. The number of Pfam homologs was smaller in sheep, horse and pig because the number of protein sequences for sheep, horse and pig was small in Uniprot. It is also seen that virtually all the proteins known in these species had homologs among cattle proteins. Thus, the functional similarities between the proteins with defined sequences from different species appeared quite amply characterized relying on Pfam.

The same Pfam domain could be present in many different proteins in a species. Say, the bovine protein ACOD_BOVIN could have the PFO0487 domain. It occurred in 27 different proteins in sheep, rat, pig, human and mouse. Obviously, a group of homologs could contain both orthologs and paralogs. However, we were interested in genes whose products could perform a similar function in different species. Their evolutionary relationships and consequently classification of homologs according to orthologs and paralogs were disregarded. It may be assumed that common Pfam domains justified the reference of proteins to the same functional family and, accordingly, supported their potential involvement in the same biological processes.

\section{Identification of homologs (HomoloGene)}

Homologs from HomoloGene are computed according to gene families. Only Rat, Human and Mouse species describe families in common with the Bovine species.

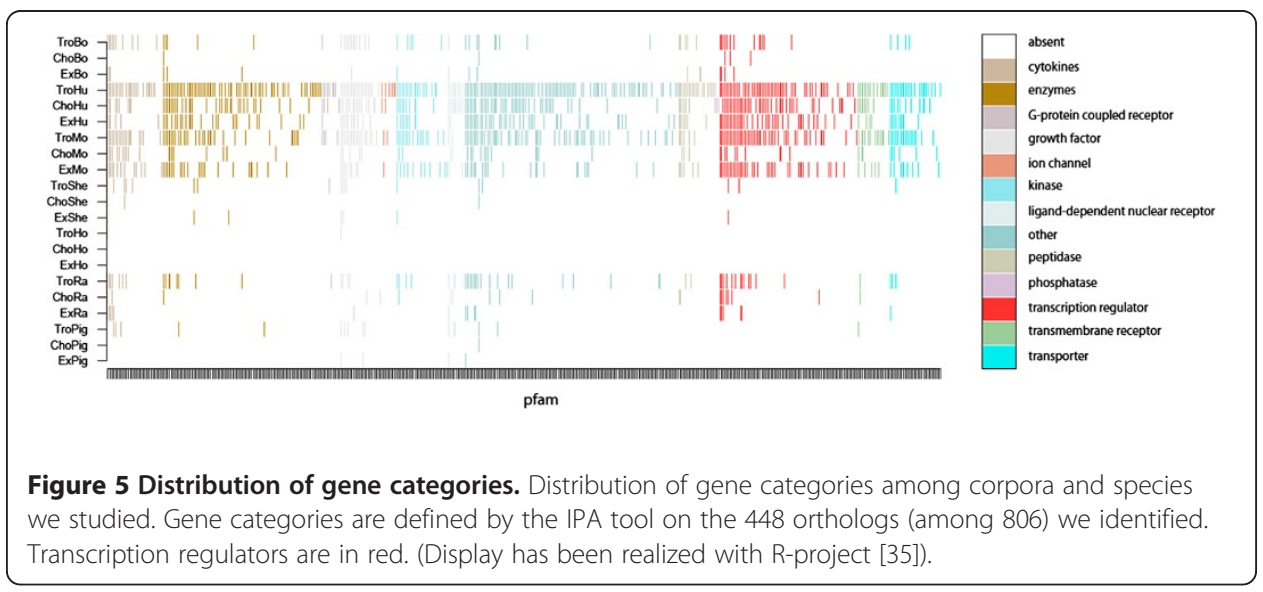


Intersection between families ID is computed to export lists of homologs between Bovine and Human, Bovine and Mouse, and Bovine and Rat. Table 1 shows amounts of homologs between these three species and Bos taurus.

\section{Filtering by a document corpus}

Proteins consisting of a single Pfam domain were more numerous than the total number of Pfam IDs describing all the protein domains of a species (for example, for mouse 9,305 against 3,978). Therefore, we had more than one Pfam homolog per protein. It seems plausible that not all the Pfam homologs of a particular protein act in the same tissues of a model organism and participate in similar processes. This demonstrated that the Pfam database alone did not solve the problem of the one-to-one correspondence between bovine and model organism proteins. Thus, additional tools to reduce the number of Pfam homologs were required. Our hypothesis space consisted of seven species (cattle, pig, sheep, horse, human, mouse and rat) and three tissue types (extraembryonic tissues, trophoblast, and choriocarcinoma). Taking this into account, 21 subcorpora were created (see Table 2).

The following query was defined to generate the corpora from the PubMed and the WoS databases:

Table 2 Number of documents

\begin{tabular}{|c|c|c|c|c|}
\hline Corpus & Description & PubMed & WoS & Fusion \\
\hline Tropho & $\begin{array}{l}\text { Corpus about trophoblast, extraembryonic tissues and } \\
\text { choriocarcinoma }\end{array}$ & 20,132 & 25,702 & 33,798 \\
\hline HuMo & Corpus about human/proliferation and mouse/development & 111,862 & & \\
\hline \multicolumn{5}{|c|}{ Subcorpus name } \\
\hline TroBo & trophoblast and bovine & 409 & 473 & 583 \\
\hline ChoBo & choriocarcinoma and bovine & 33 & 27 & 39 \\
\hline ExBo & extraembryonic tissues and bovine & 47 & 39 & 58 \\
\hline TroHu & trophoblast and human & 4,976 & 4,762 & 6,336 \\
\hline $\mathrm{ChoHu}$ & choriocarcinoma and human & 2,023 & 1,745 & 2,553 \\
\hline ExHu & extraembryonic tissues and human & 519 & 417 & 623 \\
\hline TroMo & trophoblast and mouse & 1,724 & 1,478 & 2,064 \\
\hline ChoMo & choriocarcinoma and mouse & 268 & 181 & 308 \\
\hline ExMo & extraembryonic tissues and mouse & 1,081 & 928 & 1,252 \\
\hline TroRa & trophoblast and rat & 564 & 492 & 701 \\
\hline ChoRa & choriocarcinoma and rat & 156 & 123 & 191 \\
\hline ExRa & extraembryonic tissues and rat & 124 & 90 & 154 \\
\hline TroHo & trophoblast and horse & 59 & 66 & 82 \\
\hline $\mathrm{ChoHo}$ & choriocarcinoma and horse & 5 & 3 & 6 \\
\hline ExHo & extraembryonic tissues and horse & 8 & 7 & 12 \\
\hline TroPig & trophoblast and pig & 206 & 178 & 263 \\
\hline ChoPig & choriocarcinoma and pig & 8 & 4 & 8 \\
\hline ExPig & extraembryonic tissues and pig & 29 & 28 & 36 \\
\hline TroShe & trophoblast and sheep & 376 & 357 & 505 \\
\hline Choshe & choriocarcinoma and sheep & 21 & 19 & 25 \\
\hline ExShe & extraembryonic tissues and sheep & 44 & 47 & 60 \\
\hline
\end{tabular}

Number of processed documents per corpus and subcorpus. 
((trophoblast* or choriocarcinoma* or extra-embryonic* or extraembryonic*) and (bovine or human or pig or sheep or mouse or rat or horse))

PubMed is specialized in biomedical documents, but use of WoS is quite complementary and enriches by $20 \%$ the initial corpus. The first script was written, considering keywords from the query, to divide these two global corpora (WoS and PubMed) into 21 subcorpora. The second script was used to merge each subcorpus pair (PubMed and WoS) into a single subcorpus avoiding document duplicates. Additional file 2 shows the number of documents per subcorpus and the original global corpus ('Tropho'). We noticed that some subcorpora were poorly documented including 'ExBo,' $\mathrm{ChoHo'} \mathrm{or} \mathrm{'ChoPig'} \mathrm{(Additional} \mathrm{file} \mathrm{2).}$

However, as reported by [3], using pig, sheep or horse species in this study likely limited the size of information to be mined. Therefore, a more general corpus has also been created, including only the human and mouse model species. Firstly a query for human has been created to generate a subcorpus called "Human Proliferation" from PubMed. It contained 77,333 documents. Keywords used were:

$$
\begin{aligned}
& \text { Query }=\text { \#req1 OR \#req2 OR \#req3 OR \#req4 } \\
& \text { \#req4 = human AND embryo Field: Title/Abstract, Limits: Humans } \\
& \text { \#req3 = human AND embryo Field: MeSH Terms, Limits: Humans } \\
& \text { \#req2 = human AND placenta AND cancer Field: Title/Abstract, Limits: Humans } \\
& \text { \#req1 = human AND placenta AND cancer Field: MeSH Terms, Limits: Humans }
\end{aligned}
$$

A second subcorpus called "Mouse Development" had also been generated from PubMed. It contained 34,529 documents. Keywords used were:

$$
\begin{aligned}
& \text { Query }=\text { \#req1 OR \#req2 } \\
& \text { \#req1 = mouse AND embryo Field: Mesh Terms, Limits: Animals } \\
& \text { \#req2 = mouse AND embryo Field: Title/Abstract, Limits: Animals }
\end{aligned}
$$

Globally their fusion led to a dictionary of 256,133 tokens.

We then considered the frequency of occurrence, in the publications, of words with similar meanings. For example, extraembryonic is a rare word in the literature concerning cattle since the word "trophoblast" is more often used to designate the extraembryonic tissues. Indeed, the latter word comes from the mouse literature. The word "choriocarcinoma" is not very much applied to livestock species, since it comes from the medical community. Indeed, no choriocarcinoma has ever been described in these species (cattle, sheep, pig, horse), although (i) ectopic grafts of pig trophoblast cells seemed to adopt a tumorigenic phenotype (ii) a rat choriocarcinoma-derived cell line (Rcho-1) as well as (iii) human choriocarcinomaderived lines (JEG-3, JAR, BEWO; http://www.cell-lines-service.de) were established. As mentioned above with reference to the processing of general corpora, from each subcorpus a dictionary of unique lexical units (i.e., tokens) was established. Additional file 2 shows the number of such units in each subcorpus. Each dictionary was then used to filter (by presence/absence) the list of Pfam homologs.

As known, some genes may have several functions and act in different tissues. When applied to a process, this filtering may be regarded as heuristic, (useful for knowledge 
discovery), ensuring filtering of genes playing a role in the process: trophoblast development, for example (Table 3) shows the number of Pfam homologs filtered by subcorpora). The whole set of Pfam homologs with the bovine domains were present in all corpora, that is to say, in all tissues and species tested, and was composed of 1,155 genes and 153 TF (Additional file 3). We observed that usage of synonyms improved the search in dictionaries and increased the number of detected genes (Table 3, right column). The list of genes identified in the text was enriched by $30 \%$.

We envisioned two options to reorganize this list of genes beyond their interaction context. The first relied on identification of their transcription regulatory properties in relation to differentiation pathways. In so doing, we identified 15 to $20 \%$ of these homologs as transcription regulators and analyzed their distribution among corpora (Figure 5). Human and mouse corpora were rich in these factors, as compared to the rat or bovine corpora. In contrast, as feared, pig, sheep and horse corpora were poorly documented in this regard. The second option to reorganize the list was related to a sorting operation by score computation. The last one would be a screening for growth factors, cytokines or kinases linked to the cell cycle. We realized that cytokines and growth factors were much less represented than transcription regulators in the main corpora (human, mouse). Interestingly, kinases were similarly well documented in the human and mouse "tro" corpora but

Table 3 Number of Pfam homologs per subcorpus

\begin{tabular}{|c|c|c|}
\hline Subcorpus name & Pfam homologs with synonyms & Pfam homologs (without synonyms) \\
\hline TroBo & 108 & 87 \\
\hline ChoBo & 15 & 10 \\
\hline ExBo & 35 & 35 \\
\hline TroHu & 551 & 380 \\
\hline $\mathrm{ChoHu}$ & 297 & 193 \\
\hline ExHu & 167 & 152 \\
\hline TroMo & 336 & 241 \\
\hline ChoMo & 74 & 51 \\
\hline ExMo & 199 & 146 \\
\hline TroRa & 120 & 74 \\
\hline ChoRa & 43 & 27 \\
\hline ExRa & 28 & 16 \\
\hline TroHo & 2 & 4 \\
\hline $\mathrm{ChoHo}$ & 0 & 0 \\
\hline ExHo & 0 & 0 \\
\hline TroPig & 24 & 18 \\
\hline ChoPig & 2 & 1 \\
\hline ExPig & 5 & 6 \\
\hline TroShe & 29 & 23 \\
\hline ChoShe & 5 & 3 \\
\hline ExShe & 8 & 9 \\
\hline Total & 806 & 569 \\
\hline
\end{tabular}


less documented in the "cho" corpora. This may indicate their tissue-specificity and open new areas of data-mining.

\section{Classification of genes - presence score in subcorpora}

The classification is intuitive enough, therefore interpretable, and easily tractable. It is based on the identification of genes typical of processes or species. The key is the presence (or absence) of a gene within a subcorpora. Such a classification is the final result of the general workflow (see Figure 3). For this purpose, we created a matrix of scores. There are $\mathbf{n}$ genes and $\mathbf{m}$ subcorpora, let $\mathbf{S}$ be the matrix of scores of the gene set $\mathbf{G}=\left\{\mathrm{g}_{1}, \ldots, \mathrm{g}_{\mathrm{n}}\right\}$ by the set of subcorpora $\mathbf{C}=\left\{\mathbf{c}_{1}, \ldots, \mathrm{c} \mathrm{m}_{\mathrm{m}}\right\} . \mathbf{S}_{\mathbf{i j}}$ is defined such as $\mathbf{s}_{\mathbf{i j}}=1$, if a gene $\mathbf{g}_{\mathbf{i}}$ is present in the subcorpus $\mathbf{c}_{\mathbf{j}}$, otherwise $\mathbf{s}_{\mathbf{i j}}=0$. Below we show the algorithm:

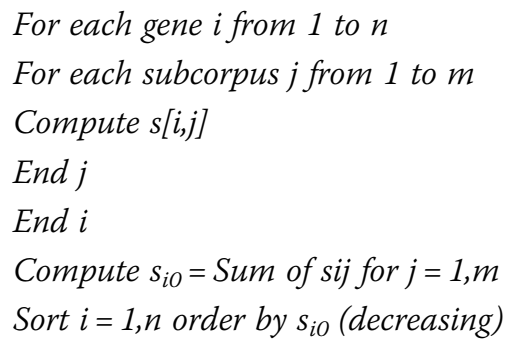

Our final filtering step led us to $\mathbf{n}=806$ genes using $\mathbf{m}=21$ subcorpora and the first 50 top genes sorted by rank $\left(\mathbf{s}_{\mathbf{i} \mathbf{0}}>=9\right)$, were potentially selected by biologists for further validations.

\section{Classification of genes - frequency score in subcorpora and PubMed}

The second approach to sort the gene list was the extraction of the more or less specific genes with regard to the process of interest. This meant study of the specificity of a gene described by one or more subcorpora with regard to the whole space of knowledge (WoS and PubMed). Technically, we assigned a smaller weight to a gene occurring very frequently in PubMed. In our workflow, this concerned the processing part in the grey frame (Figure 4).

In computation, we used the classical score in the information retrieval and called tf-idf [36]. This weight takes into account the relative importance of a term (i.e., word or phrase) in a document (it is the 'term frequency' or the 'tf' part in the score), with a modulation by inverse of the ratio defined by the total number of documents divided by the number of documents containing the term (it is the 'inverse document frequency' or the 'idf' part of the score). Normalization of the frequency by the size of the documents ensured comparisons of documents of different sizes. In our case, a term was a gene name with its synonyms. The total number of documents in the PubMed and in the subcorpora was used to work out the tf-idf. For a given gene, name normalization is defined by the number of documents of all subcorpora containing this gene name.

To compute the 'tf' part of a score, we proceed as follows. Let $\boldsymbol{g}_{\boldsymbol{i}}$ be the name of gene $\boldsymbol{i}, \boldsymbol{n}_{\boldsymbol{i}}$ be the number of corpus documents containing $\boldsymbol{g}_{\boldsymbol{i}}, \boldsymbol{j}$ be the index of the subcorpus 
containing at least one document with $g_{i}$ and $N_{j}$ be the number of documents of subcorpus $\boldsymbol{j}$. Thus,

$$
t f_{i}=\frac{n_{i}}{\sum_{j} N_{j}}
$$

It is the importance of a gene in subcorpora.

The 'idf' part was computed as follows. Let $\mathbf{D}$ be the number of documents in PubMed, and $\mathbf{G F}_{\boldsymbol{i}}$ be the number of documents in PubMed which contain the name of $i$-th gene, then:

$$
i d f_{i}=\log \frac{D}{G F_{i}}
$$

Finally, the score of classification for gene $i$ is $\mathbf{w}_{\mathbf{i}}=\mathbf{t f}_{\mathbf{i}} \cdot \mathbf{i d f}_{\mathbf{i}}$.

Below we present the algorithm:

For each gene i from 1 to $n$

Compute GF[i]

End $i$

For each gene i from 1 to $n$

For each sub corpus $j$ from 1 to $m$

compute $n[i, j]$

End $j$

Compute $S C=\operatorname{Sum}|N[j]|$ from $j=1, m$ if $n[i, j]$ is not $N U L L$

Compute tf[i] $=n[i] / S C$

Compute idf[i] $=\log (D / G F[i])$

Compute $w[i]=t f[i] i d f[i]$

End $i$

Sort $i=1, n$ order by $w[i]$ (decreasing)

and the results obtained by both classifications (presence/absence and tf-idf) led to a short-list about the 50 top genes over all subcorpora. Each kind of computed score places different genes at the top of the lists, six genes are common: feta, cata, ntri, soma, sprc, ty3h. Interpreting general functions given by Gene Ontology in both lists (computed with the two different scores), we observed that they are very close to our initial issue and indicate development and proliferation, however, few TF were identified in these short lists, thus highlighting the risks of the ranking procedures as well as the risk of treating only an "emerging part" of the datasets for further validations.

\section{Revealing transcription factors among top-ranked genes}

Using dictionaries for Human Proliferation and Mouse Development we obtained - out of 18,670 genes isolated from of the bovine genome - (i) 4,794 orthologs with the 2 "Human-Mouse" subcorpora and (ii) 1,155 candidates using the previous 21 subcorpora. Taking advantage of studies that reported gene expression profiles during the elongation of bovine embryos [5,12,30,37-43], we (i) defined a list of transcription regulators (TR, $\mathrm{n}=70$ ) among which we kept the transcription factors only (TF, $\mathrm{n}=64$; Table 4) and - from the terminology of the data mining domain - (ii) used it as a "gold 
Table 4 Biological gold standard for transcription factors

\begin{tabular}{lllll}
\hline ASCL2/MASH2 & EOMES & HOXB9 & KLF9 & SIX2 \\
CDX2 & ETS1 & HOXC4 & MSX1 & SIX3 \\
c-fo5 & ETS2 & HOXD10 & MXI1 & SOX13 \\
CITED1 & FOSB & HOXD11 & MYB & SOX15 \\
CITED2 & FOXA2 & HOXD13 & MYC & SOX17 \\
DLX2 & GATA2 & JUN & OSTF1 & SOX2 \\
DLX3 & GATA3 & JUND & OTX2 & SP1 \\
DLX4 & GATA4 & KLF10 & PAX9 & SPARC \\
DLX5 & GATA5 & KLF13 & PHB & STAT2 \\
DNMT1 & KLF15 & PHLDA1 & TBX10 \\
DNMT3A & GATA6 & KLF3 & PITX2 & TBX15 \\
DNMT3B & HAND1 & KLF4 & SALL1 & TBX18 \\
ELF2 & HNF4A & KLF5 & TBX5 \\
\hline
\end{tabular}

64 genes generating our biological Gold Standard for Transcription Factors identified so far as differentially expressed in bovine embryos during the elongation process [mainly 30,37,42].

standard" to assess the quality of our approach. Considering the gold standard gene set and the TF lists that were identified through our analyses, we got the following scores: (i) $95.3 \%$ recall with the "Human-Mouse" subcorpora (3 non-retrieved genes: KLF15, PHLDA11, TBX15 due to unrecognized gene ID depending on the species or databases), (ii) $59.4 \%$ recall with the 21 subcorpora (26 non-retrieved genes, likely due to restricted gene resources) and (iii) $17.2 \%$ recall using the 'top 100' genes from the 21 subcorpora, following a ranking by "presence/absence" within these subcorpora (53 non retrieved genes with the workflow).

At first, one could think: "the larger the gene list, the larger the TF content", however, this is not the case because of a plateau (Figure 6) and 2 TF-identification slopes for the ranges of 0 to 2,500 and 2,500 to 5,000 gene IDs. Moreover, 2 converging arguments came from the literature to reinsure these observations: i) not more than $873 \mathrm{TF}$ were identified over 11,795 genes and 32 human adult tissues, using an Affymetrix gene chip, even if some tissues exhibit more TF than others: brain and placenta for example

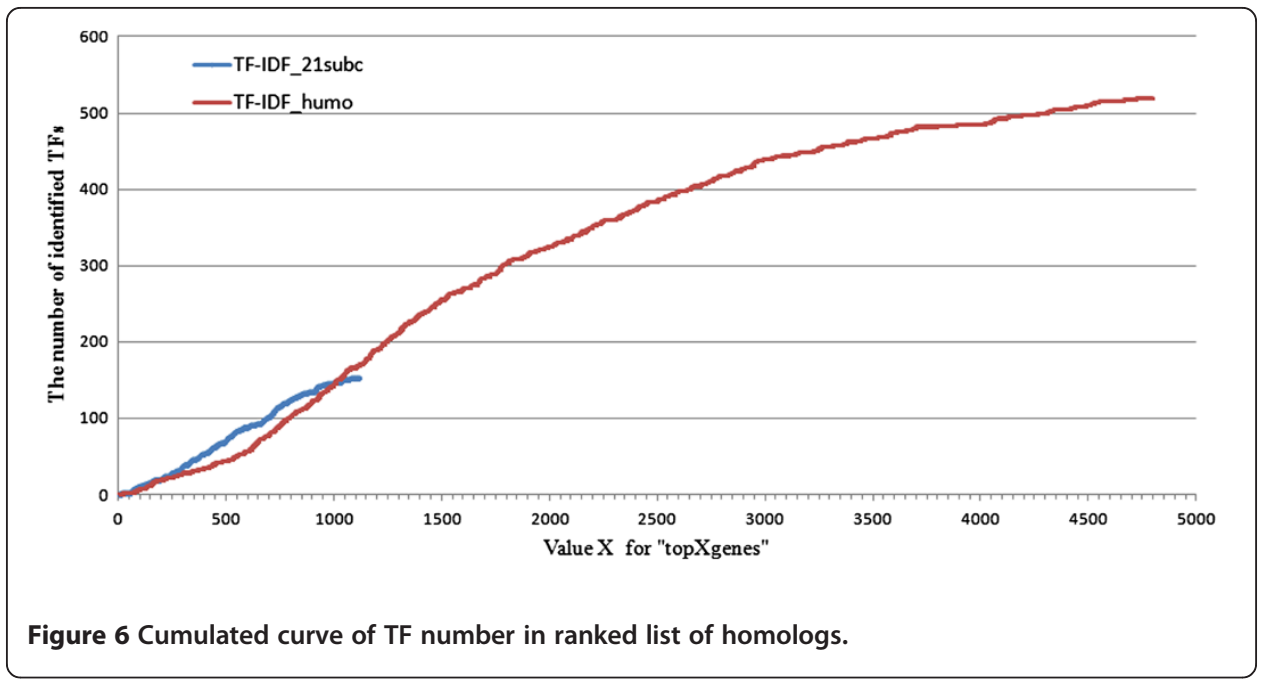


[4], ii) across 24 eukaryotic genomes from yeast to chimpanzee, not more than 1,391 TF were considered as an evolutionary repertoire of TF [4].

Nevertheless, considering the largest corpus led to the highest recall (95\%). Indeed, among the 4,794 homologs, 523 gene IDs were recognized as TF and among these, 489 had a Pfam domain which was used to confirm their main role of "DNA binding" function (Figure 6). Moreover, 246 of these IDs were identified as present within 2 gene expression datasets on bovine elongating embryos (Figure 7). At last, the 243 gene IDs (Additional file 4) that were not in these datasets were however "true" TF since 95\% $(n=231$; Figure 8) were properly classified by the TF encyclopedia, the other $5 \%$ corresponding to unrecognized gene ID or synonyms. Interestingly enough, most of the TF identified here belonged to the homeodomain family (Figure 8), a characteristic family for developmental processes and tissues [4] and a sign of relevant TF classes with our mining approach and workflow.

However, as underlined by [4], some TF are present in all or most tissues with similar expression levels, thus being ubiquitous TF, while others are selectively expressed in a few tissues, thus bringing specific tissue signatures. Therefore, it is clear that among the 489 TF identified by our approach, only a part will contribute to an extra-embryonic, a trophoblastic or an elongating signature. That is also why the analysis through species and tissues (21 subcorpuses) may help sorting out expression specificities, before further biological investigations. As an example, the transcription regulators from these subcorpuses that did not belong to the "gold standard" revealed interesting biological features: i) ESR1 is involved in proliferation and development of various tissues [44] and expressed in bovine placenta [45], ii) HES1 is involved in embryonic patterning [46] and mediates differentiation into mouse trophoblast giant cells [47], iii) Id2

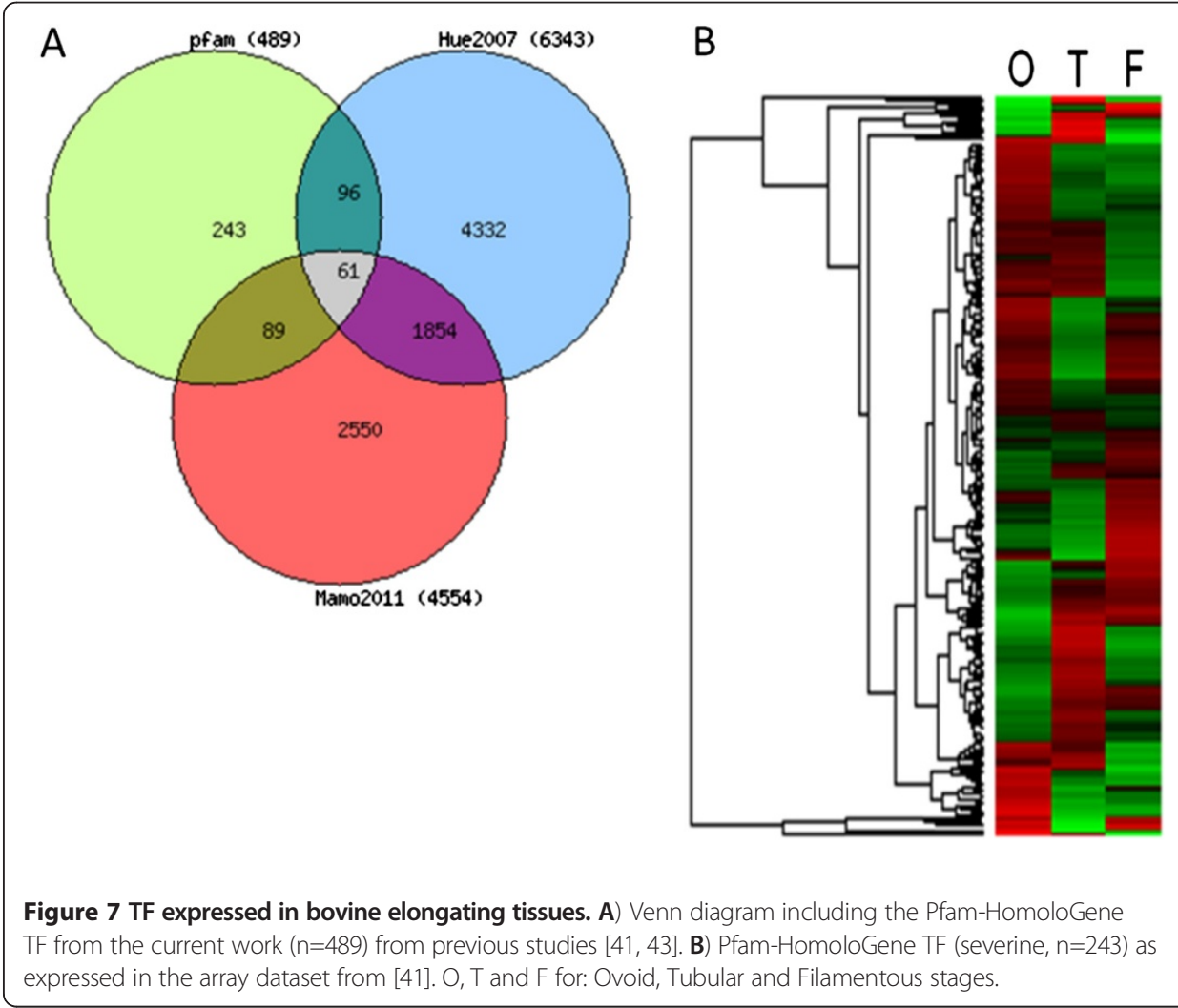




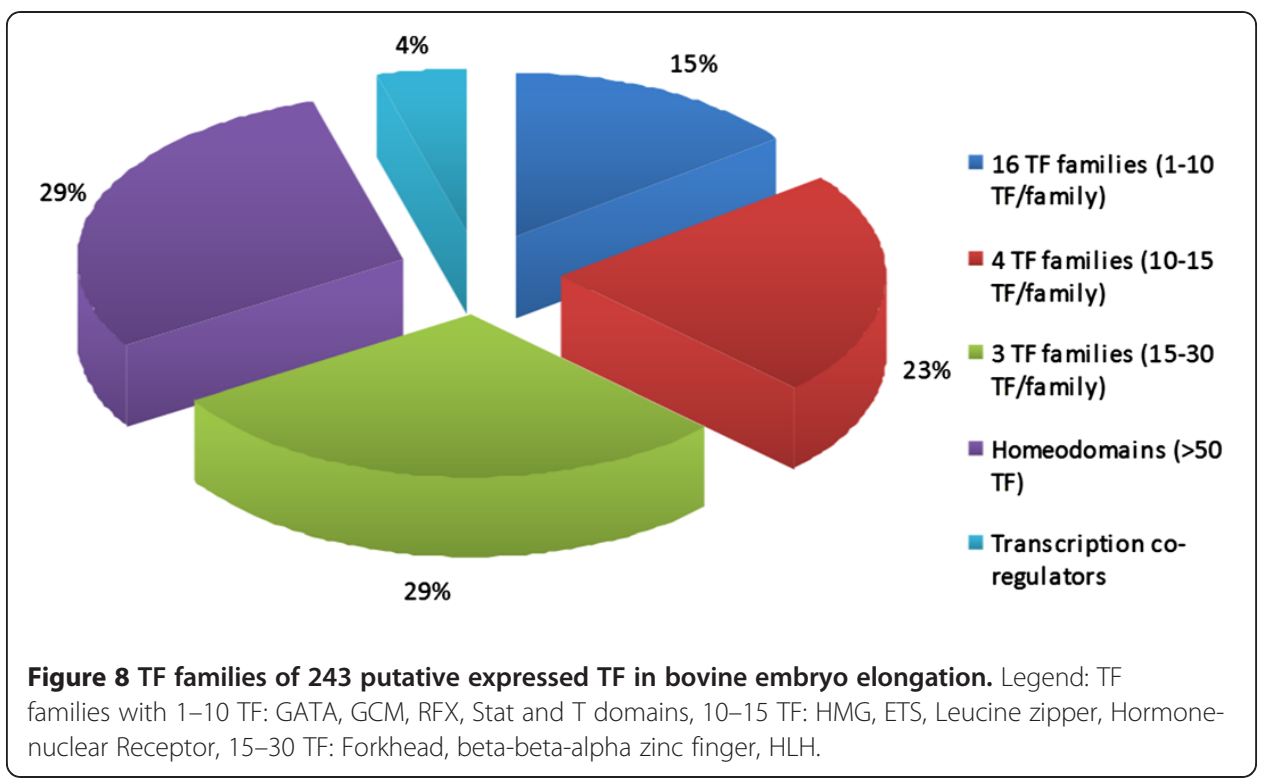

mediates signaling by activating the proto-oncogene $M y c$ [48] and can be downregulated by TGF-beta signaling to favor differentiation, as evidenced in trophoblast stem cells [49], iv) NANOG is required for the maintenance of cellular pluripotency during normal development as well as in cultured embryonic stem cells but has been detected in bovine extra-embryonic tissues [37], v) P53 regulates the cell cycle and functions as an apoptosis regulator in human villous trophoblast cells [50] and vi) PHB2 is a transcription coregulator, initially identified as a repressor of estrogendependent transcriptional activity. Furthermore, it appeared that all these genes had interesting patterns during elongation with ID2 increasingly transcribed and PHB2 decreasingly transcribed from the ovoid to the filamentous stage, whereas HES1peaked at the tubular stage.

\section{Discussion}

Elongation, i.e., the lengthening and morphological transition of the conceptus from a sphere to ovoid, tubular and filamentous shapes (Figure 1) provides an increased surface area to enable maternal-conceptus cross-talk and nutrient exchanges [51]. Accompanying elongation is the degradation of the sheath of trophoblast cells covering the embryonic disc (Rauber's layer) exposing the cells of the embryonic disc to the maternal milieu [52]. The trophoblast is an epithelium and its development combines many biological processes among which proliferation and differentiation. The trophoblast from ruminants does not attach to the uterus of the mother as the trophoblast of rodents and primates do: no invasion, no implantation at a single site and no hemochorial placenta. Total metabolism and protein trafficking are characteristic of the onset of elongation, whereas cellular interactions, cell to cell signaling and cell adhesion become prevalent at the end of it $[6,30,53]$. Recent results confirmed that an intense multiplication of a non-fully differentiated trophoblast has to be considered at the onset of elongation [37]. However, few data on the molecular bases of this proliferation have been reported in cattle, while they were well documented in such areas as human 
cancer or human trophoblast development. Since differentiation occurs during elongation and since mouse corpora are well documented for proliferation and differentiation, it was satisfying that our workflow identified on the "human-mouse" corpora the highest number of TF with the best recall of the "gold standard" gene set. Interestingly, the 21 subcorpora identified less transcription factors and genes from the gold standard, but highlighted other genes of interest, such as cytokines or growth factors. Indeed, early implantation is known to be facilitated by an acute inflammatory response of the uterus, a process orchestrated by the trophoblast through the augmentation of cytokine responses [54], and the trophoblast we studied here is only a few days ahead of implantation. The ranking procedures thus helped for gene selection.

Returning to the 806 Pfam homologs, the distribution of genes across subcorpora (Figure 5) reveals that TroHu is close to TroMo, ChoHu and ExMo, suggesting some closeness between species or tissues. Let us assume for further analysis of interactions that (i) species like human and mouse, or bovine and rat can be gathered in only 2 corpora, (ii) tissues may also be gathered or discriminated on the basis of proteins of interest (cytokines or growth factors, for example); All. This could be done to extract common and specific features for sub-classes of species or tissues and refined to screen for:

- other genes (cytokines, growth factors, kinases...) or links to other proteins along pathways from the cell membrane to the nucleus

- sub-cellular locations through bioinformatics databases [55] or histological atlases

[56], hunting for co-expressed genes

and thus, work on text mining data to build interaction maps.

\section{Conclusions}

We created a workflow to search for genes of interest through (1) crossing information from several databases (tables for protein knowledge and raw text) and (2) furnishing a gene list to manage economy in biological testing.

The developed workflow is a mining analytical methodology leading to selection of characteristics of biological processes according to gene and protein properties disseminated in several databases. The originality is highly related to (i) exploration of biomedical text database to make a powerful semantic filter for expression context of genes (ii) use subcorpora resulting from this filtering and (iii) use fused resources: text and biology. The suggestion to build corpuses, in order not to explore the whole text database, relies on the internal structure of language - based on reuse of words and phrases making them ambiguous; a corpus is a kind of "unstructured" knowledge base of biological facts that may be considered as "cleaned" enough, i.e. containing solely facts about the subject (in our case tissues and species). The ultimate result is a list of Pfam-HomoloGene homologs containing about 15 to $20 \%$ of transcription regulators as well as shorter lists of sorted genes (cytokines, kinases. . .) that could now be the objects of further refined mining.

The workflow can now serve as a new kind of bioinformatics tool to work on fused data sources (raw text and biology) and can thus be useful in studies of a wide range of biological processes. 


\section{Additional files}

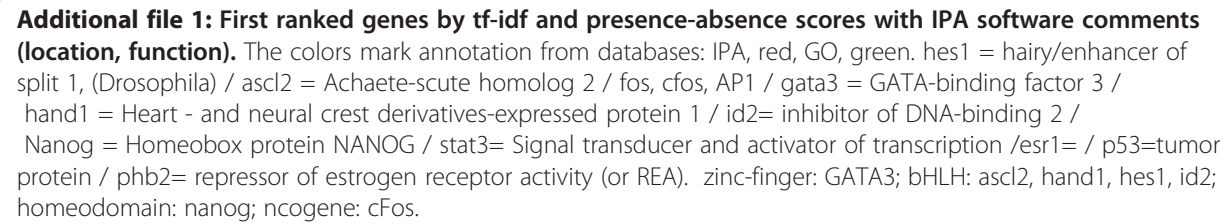

Additional file 2: Dictionaries. Dictionary sizes (list of all lexical forms) for each corpus and subcorpus.

Additional file 3: Distribution of TF families for $153 \mathrm{TF}$ identified by pfam-homologene and 21 subcorpora. TF domains were identified with TF encyclopedia.

Additional file 4: List of putative expressed TF for Bovine embryo. 243 putative TF for bovine elongating tissues; Could however be partly present within the recent RNA sequencing data set, which was published in 2012 and was not included here [57]. In pink, the gene IDs that were not recognized by the TF encyclopedia; in blue, the TF families that were identified through the use of synonyms for these IDs.

\section{Competing interests}

The authors declare that they have no competing interests.

\section{Authors' contributions}

$N T, I H, V I, E T$ designed, performed the study. NT, ET, PD, SAD, El and DV were involved in data analysis. NT drafted the manuscript. $\mathrm{ET}, \mathrm{IH}, \mathrm{VI}, \mathrm{El}$ and $\mathrm{NY}$ corrected the manuscript. All authors read and approved the final manuscript.

\section{Acknowledgements}

The authors are grateful to Nikolay Kolchanov, the Director of Institute of Cytology and Genetics SB RAS (Novosibirsk), for accepting research visits during this study. They are also grateful to INRA for agreement for exchanges and grant MIG SE-1077. DV is a PhD with a DGER/INRA fellowship; SAD was a "Conseil Régional d'lle-de-France" Postdoctoral fellow. VI, ET, El were partly supported by the Ministry of Science and Education of the Russian Federation (Contracts NN 14.740.11.0001, 5278.2012.4, SD RAS (NN 87,136, V1.50.1.2), RAS (Program "№28.2", and № 6.8) and FP7: EU-FP7 SYSPATHO No. 260429. Thanks to Anna Fadeeva for editing the English translation and to Pavel Demenkov (ICG, Novosibirsk) for help with PubMed management.

\section{Author details}

${ }^{1}$ INRA, SenS, UR1326, IFRIS, Champs-sur-Marne F-77420, France. ${ }^{2}$ Sector of Computational Proteomics, Institute of Cytology and Genetics, 10 Lavrentyev Ave, Novosibirsk 630090, Russia. ${ }^{3}$ INRA, UMR1198 Biologie du Développement et Reproduction, Jouy-en-Josas F-78352, France. ${ }^{4}$ ENVA, Maisons Alfort F-94704, France. ${ }^{5}$ Laboratory of Animal Molecular Genetics, Institute of Cytology and Genetics, 10 Lavrentyev Ave, Novosibirsk 630090, Russia. 'Laboratory of Evolutionary Bioinformatics and Theoretical, Institute of Cytology and Genetics, 10 Lavrentyev Ave, Novosibirsk 630090, Russia.

Received: 10 October 2011 Accepted: 15 August 2012

Published: 29 August 2012

\section{References}

1. Soldatos TG, O'Donoghue SI, Satagopam VP, Barbosa-Silva A, Pavlopoulos GA, Wanderley-Nogueira AC, SoaresCavalcanti NM, Schneider R: Caipirini: using gene sets to rank literature. BioData Mining 2012, 5:1,

2. Simpson MS, Demner-Fushman D: Biomedical text mining: a survey of recent progress. In 'Mining Text Data'. Edited by Aggarwal CC, ChengXiang Z. New York: Springer Science+Business Media; 2012:465-517.

3. Sahadevan S, Martin Hofmann-Apitius M, Schellander K, Tesfaye D, Fluck J, Friedrich CM: Introducing the potential of text mining to animal sciences. J Anim Sci 2012. doi:10.2527/jas.2011-4841.

4. Yusuf D, et al: The transcription factor encyclopedia. Genome Biol 2012, 13:R24.

5. Arnold DR, Lefebvre R, Smith LC: Characterization of the placenta specific bovine mammalian achaete scutelike homologue 2 (Mash2) gene. Placenta 2006, 27(11-12):1124-1131.

6. Blomberg L, Hashizume K, Viebahn C: Blastocyst elongation, trophoblastic differentiation, and embryonic pattern formation. Reproduction 2008, 135:181-195.

7. Ferretti C, Bruni L, Dangles-Marie V, Pecking AP, Bellet D: Molecular circuits shared by placental and cancer cells, and their implications in the proliferative, invasive and migratory capacities of trophoblasts. Hum Reprod Update 2007, 13(2):121-141. Review.

8. Knöfler M, Sooranna SR, Daoud G, Whitley GS, Markert UR, Xia Y, Cantiello H, Hauguel-de Mouzon S: Trophoblast signalling: knowns and unknowns-- a workshop report. Placenta 2005, 26(Suppl A):S49-S51.

9. El-Hashash AH, Warburton D, Kimber SJ: Genes and signals regulating murine trophoblast cell development. Mech Dev 2010, 127(1-2):1-20. Epub 2009 Sep 13. Review.

10. Hemberger M: Genetic-epigenetic intersection in trophoblast differentiation: implications for extraembryonic tissue function. Epigenetics 2010, 5(1):24-29. Epub 2010 Jan 9. Review.

11. Faria TN, Soares MJ: Trophoblast cell differentiation: establishment, characterization, and modulation of a rat trophoblast cell line expressing members of the placental prolactin family. Endocrinology 1991, 129(6):2895-2906. 
12. Bai H, Sakurai T, Kim MS, Muroi Y, Ideta A, Aoyagi Y, Nakajima H, Takahashi M, Nagaoka K, Imakawa K: Involvement of GATA transcription factors in the regulation of endogenous bovine interferon-tau gene transcription. Mol Reprod Dev 2009, 76(12):1143-1152.

13. Das P, Ezashi T, Gupta R, Roberts RM: Combinatorial roles of protein kinase A, Ets2, and 3',5'-cyclic-adenosine monophosphate response element-binding protein-binding protein/p300 in the transcriptional control of interferon-tau expression in a trophoblast cell line. Mol Endocrinol 2008, 22(2):331-343.

14. Ralston A: Rossant genetic regulation of stem cell origins in the mouse embryo. J Clin Genet 2005, 68(2):106-12.

15. Roberts RM, Fisher SJ: Trophoblast stem cells. Biol Reprod 2011, 84(3):412-421.

16. Hirschman L, Yeh A, Blaschke C, Valencia A: Overview of BioCreAtlvE: critical assessment of information extraction for biology. BMC Bioinformatics 2005, 6(Suppl 1):S1.

17. Hahn U, Wermter J, Blasczyk R, Horn P: Text mining: powering the database revolution. Nature 2007, 448(7150):130.

18. Krallinger M, Morgan A, Smith L, Leitner F, Tanabe L, Wilbur J, Hirschman L, Valencia A: Evaluation of text-mining systems for biology: overview of the second BioCreative community challenge. Genome Bio/ 2008, 9(Suppl 2):S1.

19. Ananiadou S, Pyysalo S, Tsujii J, Kell DB: Event extraction for systems biology by text mining the literature. Trends Biotechnol 2010, 28(7):381-390.

20. Aman EE, Demenkov PS, Pintus SS, Nemiatov Al, Apasieva NV, Korotkov RO, Ignatieva EV, Podkolodny NL, Ivanisenko VA: Development of a computer system for the automated reconstruction of molecular genetic interaction networks. Fifth International Conference on Bioinformatics of Genome Regulation and Structure (BGRS) 2006, 3:15-18.

21. Ivanisenko VA, Demenkov PS, Aman EE, Pintus SS, Kolchanov NA: Associative network and protein structure discovery: a software complex for facilitating search of targets for drugs, drug design, and evaluation of molecular toxicity. 3rd International conference "Basic science for medicine" 2007, 92.

22. Sommer B, Tiys ES, Kormeier B, Hippe K, Janowski SJ, Ivanisenko TV, Bragin AO, Arrigo P, Demenkov PS, Kochetov AV, Ivanisenko VA, Kolchanov NA, Hofestädt R: Visualization and analysis of a cardio vascular disease- and MUPP1-related biological network combining text mining and data warehouse approaches. $J$ Integr Bioinformatics 2010, 7(1):148.

23. Turenne N, Meszaros B: KASKAD: a plat-form to extract temporal and interaction relations for genes in texts. Saint-Petersburg: International Workshop on NanoBioTechnology (NanoBio'06); 2006.

24. Natarajan J, Berrar D, Dubitzky W, Hack C, Zhang YH, DeSesa C, Van Brocklyn JR, Bremer EG: Text mining of fulltext journal articles combined with gene expression analysis reveals a relationship between sphingosine-1phosphate and invasiveness of a glioblastoma cell line. BMC Bioinformatics 2006, 7:373. doi:10.1186/1471-2105-7-373.

25. Bjorkholm P: Comparative analysis and unification of domain-domain interaction networks. Bioinformatics 2009, 25(22):3020-3025.

26. Weston J, Elisseeff A, Zhou D, Leslie CS, Noble WS: Protein Ranking: from Local to Global Structure in the Protein Similarity Network. Proc Natl Acad Sci U S A 2004, 101(17):6559-6563.

27. Ng S, Zhang Z, Tan S, Lin K: InterDom: a database of putative interacting protein domains for validating predicted protein interactions and complexes. Nucleic Acids Res 2003, 31:251-254. I. 1.

28. Tatusov RL, Galperin MY, Natale DA, Koonin EV: The COG database: a tool for genome-scale analysis of protein functions and evolution. Nucleic Acids Res 2000, 28(1):33-36.

29. Bandyopadhyay S, Sharan R, Ideker T: Systematic identification of functional orthologs based on protein network comparison. Genome Res 2006, 16(3):428-435.

30. Ushizawa K, Herath CB, Kaneyama K, Shiojima S, Hirasawa A, Takahashi T, Imai K, Ochiai K, Tokunaga T, Tsunoda Y, Tsujimoto G, Hashizume K: cDNA microarray analysis of bovine embryo gene expression profiles during the pre-implantation period. Reprod Biol Endocrinol 2004, 2:77.

31. Schaefer U, Schmeier S, Bajic VB: TcoF-DB: dragon database for human transcription co-factors and transcription factor interacting proteins. Nucleic Acids Res 2011, 39:D106-D110.

32. Vaquerizas JM, Kummerfeld SK, Teichmann SA, Luscombe NM: A census of human transcription factors: function, expression and evolution. Nat Rev Genet 2009, 10(4):252-263.

33. Matys V, Kel-Margoulis OV, Fricke E, Liebich I, Land S, Barre-Dirrie A, Reuter I, Chekmenev D, Krull M, Hornischer K, Voss N, Stegmaier P, Lewicki-Potapov B, Saxel H, Kel AE, Wingender E: TRANSFAC and its module TRANSCompel: transcriptional gene regulation in eukaryotes. Nucleic Acids Res 2006, 34:D108-D110.

34. Fulton DL, Sundararajan S, Badis G, Hughes TR, Wasserman WW, Roach JC, Sladek R: TFCat: the curated catalog of mouse and human transcription factors. Genome Biol 2009, 10:R29.

35. R Development Core Team: R: A language and environment for statistical computing. Vienna, Austria: R Foundation for Statistical, Computing; http://www.R-project.org/. ISBN 3-900051-07-0 2011.

36. Salton G, McGill MJ: Introduction to modern information retrieval. Auckland; London: McGraw-Hill publisher; 1983.

37. Degrelle SA, Campion E, Cabau C, Piumi F, Reinaud P, Richard C, Renard JP, Hue I: Molecular evidence for a critical period in mural trophoblast development in bovine blastocysts. Dev Biol 2005, 288(2):448-460

38. Tetens F, Kliem A, Tscheudschilsuren G, Navarrete Santos A, Fischer B: Expression of proto-oncogenes in bovine preimplantation blastocysts. Anat Embryol (Berl) 2000, 201(5):349-355.

39. Degrelle SA, Lê Cao KA, Heyman Y, Everts RE, Campion E, Richard C, Ducroix-Crépy C, Tian XC, Lewin HA, Renard $J P$, Robert-Granié C, Hue I: A small set of extra-embryonic genes defines a new landmark for bovine embryo staging. Reproduction 2011, 141(1):79-89.

40. Degrelle SA, Murthi P, Evain-Brion D, Fournier T, Hue I: Expression and localization of DLX3, PPARG and SP1 in bovine trophoblast during binucleated cell differentiation. Placenta 2011, 32(11):917-920.

41. Hue I, Degrelle SA, Campion E, Renard JP: Gene expression in elongating and gastrulating embryos from ruminants. Soc Reprod Fertil Supp/ 2007, 64:365-377. Review. 
42. Clemente M, Lopez-Vidriero I, O'Gaora P, Mehta JP, Forde N, Gutierrez-Adan A, Lonergan P, Rizos D: Transcriptome changes at the initiation of elongation in the bovine conceptus. Biol Reprod 2011, 85(2):285-295.

43. Mamo S, Mehta JP, McGettigan P, Fair T, Spencer TE, Bazer FW, Lonergan P: RNA sequencing reveals novel gene clusters in bovine conceptuses associated with maternal recognition of pregnancy and implantation. Biol Reprod 2011, 85(6):1143-1151.

44. Fox EM, Andrade J, Shupnik MA: Novel actions of estrogen to promote proliferation: integration of cytoplasmic and nuclear pathways. Steroids 2009, 74(7):622-627.

45. Schuler G, Teichmann U, Taubert A, Failing K, Hoffmann B: Estrogen receptor beta (ERbeta) is expressed differently from ERalpha in bovine placentomes. Exp Clin Endocrinol Diabetes 2005, 113(2):107-114.

46. Davis RL, Turner DL: Vertebrate hairy and enhancer of split related proteins: transcriptional repressors regulating cellular differentiation and embryonic patterning. Oncogene 2001, 20(58):8342-8357.

47. Liu J, Xu W, Sun T, Wang F, Puscheck E, Brigstock D, Wang QT, Davis R, Rappolee DA: Hyperosmolar stress induces global mRNA responses in placental trophoblast stem cells that emulate early post-implantation differentiation. Placenta 2009, 30(1):66-73.

48. Lasorella A, Noseda M, Beyna M, Yokota Y, lavarone A: Id2 is a retinoblastoma protein target and mediates signalling by Myc oncoproteins. Nature 2000, 407(6804):592-598.

49. Selesniemi K, Reedy M, Gultice A, Guilbert $\sqcup$, Brown TL: Transforming growth factor-beta induces differentiation of the labyrinthine trophoblast stem cell line SM10. Stem Cells Dev 2005, 14(6):697-711.

50. Heazell AE, Crocker IP: Live and let die - regulation of villous trophoblast apoptosis in normal and abnormal pregnancies. Placenta 2008, 29(9):772-783.

51. Betteridge K, Flechon JE: The anatomy and physiology of pre-attachment bovine embryos. Theriogenology 1988, 29:155-187.

52. Chang MC: Development of bovine blastocyst with a note on implantation. Anat Rec 1952, 113:143-161.

53. Cammas L, Reinaud P, Dubois O, Bordas N, Germain G, Charpigny G: Identification of differentially regulated genes during elongation and early implantation in the ovine trophoblast using complementary DNA array screening. Biol Reprod 2005, 72(4):960-967.

54. Warning JC, McCracken SA, Morris JM: A balancing act: mechanisms by which the fetus avoids rejection by the maternal immune system. Reproduction 2011, 141:715-724. Review.

55. Zhang YQ, Li T, Yang CY, Li D, Cui Y, Jiang Y, Zhang LQ, Zhu YP, He FC: Prelocabc: a novel predictor of protein sub-cellular localization using a bayesian classifier. J Proteomics Bioinform 2011, 4:1.

56. Pontén F, Jirström K, Uhlen M: The human protein atlas-a tool for pathology. $J$ Pathol 2008, 216(4):387-393.

57. Mamo S, Mehta JP, Forde N, McGettigan P, Lonergan P: Conceptus-endometrium crosstalk during maternal recognition of pregnancy in cattle. Biol Reprod 2012, 87(1):6.

doi:10.1186/1756-0381-5-12

Cite this article as: Turenne et al:: Finding biomarkers in non-model species: literature mining of transcription factors involved in bovine embryo development. BioData Mining 2012 5:12.

\section{Submit your next manuscript to BioMed Central and take full advantage of:}

- Convenient online submission

- Thorough peer review

- No space constraints or color figure charges

- Immediate publication on acceptance

- Inclusion in PubMed, CAS, Scopus and Google Scholar

- Research which is freely available for redistribution

Submit your manuscript at www.biomedcentral.com/submit 